\title{
Application of the Green Revolution Game
}

\author{
Maria Bostenaru Dan \\ Faculty of Geography, University of Bucharest, Bucharest, Romania \\ Email: Maria.Bostenaru-Dan@alumni.uni-karlsruhe.de
}

Received 18 May 2015; accepted 22 June 2015; published 25 June 2015

Copyright (C) 2015 by author and Scientific Research Publishing Inc.

This work is licensed under the Creative Commons Attribution International License (CC BY).

http://creativecommons.org/licenses/by/4.0/

(c) (i) Open Access

\section{Abstract}

The Green Revolution Game is employed in teaching in various universities. Here we review employment in two universities: the Karlsruhe University in Germany and the Ohio University in the US. The game is used not only as simulation, but also as basis to generate data for study projects. In this context, several aspects will be followed: the analysis of education approaches (including between real and virtual), the analysis of the employability of game theory for simulating hazards connected to water scarcity in the cultivation of rice, and the connection to real life situations, targeting at the transferability of this game thought for India for the situation in Italy where high yield rice and turning towards (urban) agriculture came decades later. The site considered in Italy is the one making $95 \%$ of production, Pavia. Rice fields are artificial wetlands, and consideration is given to which kind of agriculture can conserve biodiversity and lead to sustainability.

\section{Keywords}

Rice, Game Theory, Education, Pavia, Virtual Mobility, Urban Agriculture, Drought, Water

\section{Introduction}

The Expo 2015 in Milan is dedicated to "Feeding the planet, energy for life”. Milan, just 40 km north of Pavia, which contains the major part of Italian rice production (more than 95\% according to Confalonieri and Bocchi [1]), includes in the Expo on this occasion also the Rice cluster ${ }^{1}$, including mainly Asian countries, but of course also Pavia. Takaya and colleagues [2] review the environmental conditions for rice cultivation in Europe. In Asian countries the culture of rice has led to special landscape, see here Japan ${ }^{2}$. The landscape of Pavia is given also by rice cultures, but also by other natural assets (the river of Po, the poplars), as described by [3]. In Pavia, rice cultures are found both in the agricultural landscape around the city, as also in pockets in the periphery of

\footnotetext{
${ }^{1}$ http://www.provincia.pv.it/index.php?option=com_content\&view=article\&id=4946:il-cluster-del-riso-di-expo-milano-2015-arriva-a-pavia-i l-laos-firma-il-contratto-di-partecipazione\&catid=7:notizie\&Itemid=109\&lang=it

${ }^{2}$ http://japan-magazine.jnto.go.jp/en/1504_riceterrace.html
} 
the city. Figure 1 shows a part in the North-West where these can be clearly recognized. The streets of the city have on one side the rice field and on the other the buildings. Stan [4] conducted research in the field of the landscape of urban peripheries, of the urban sprawl. Alternatively to the so-called "Zwischenstadt", an urban geography concept introduced by the German architect Thomas Sieverts, which characterizes urban sprawl (meaning: "the city in-between") the periphery can include elements of urban agriculture, that is agriculture in urban outskirts or urban vicinity, as in the work of landscape architect Nicolas Triboi (Figure 2), where instead of a new "Siedlung" (a type of settlement typical for German urban outskirts) a bio-farm was built. The situation in Pavia however is particular, the farm lots being actually pockets parks which could be grouped towards the start of a new greenway.
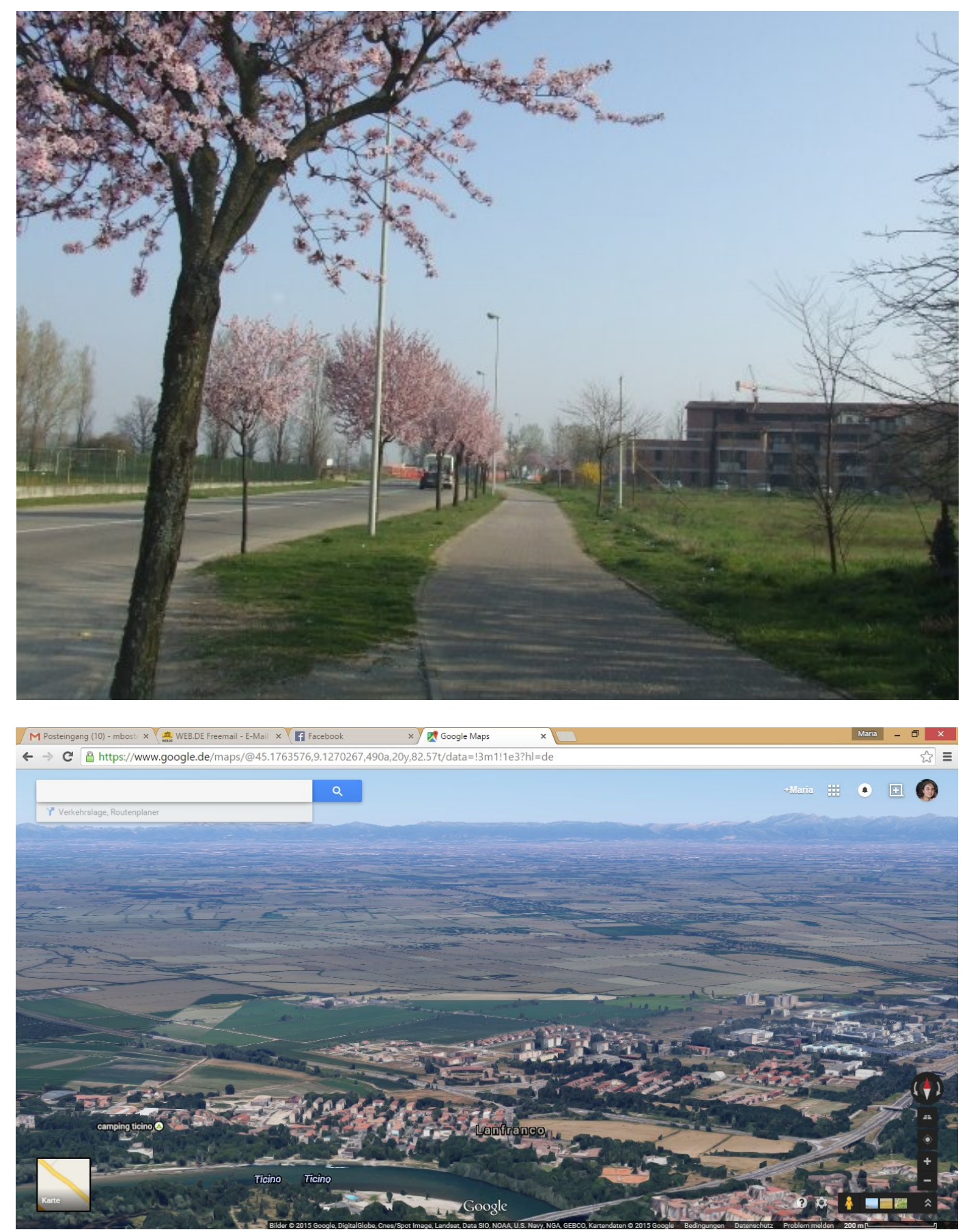

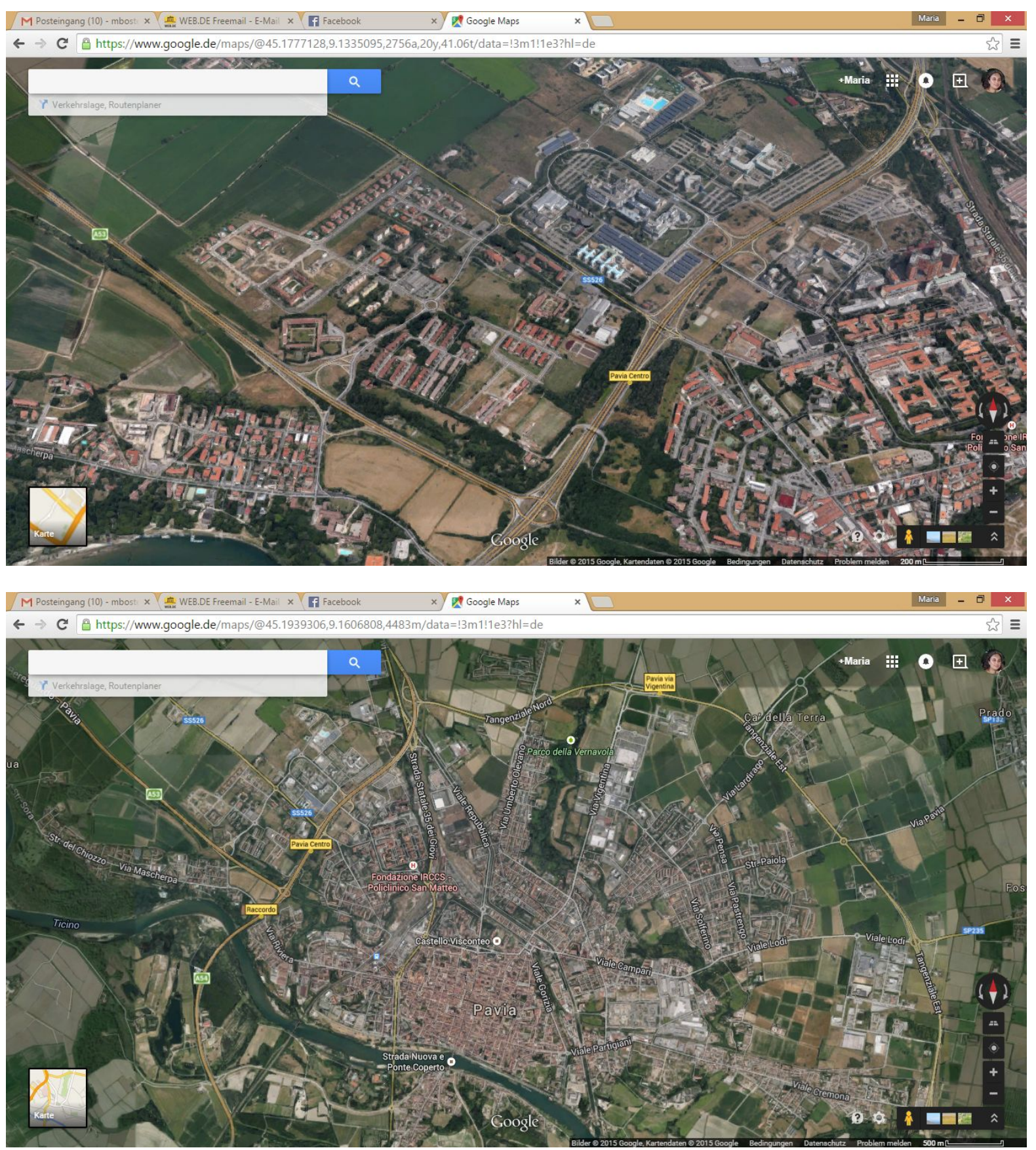

Figure 1. Image and location of rice fields in Pavia, Italy. Photo: M. Bostenaru, 2006, maps from Google earth.

Mid 20th century the Green Revolution brought a series of research and technology development initiatives in order to increase agricultural production. That time, in Europe there was an industrial revolution, but for Asian countries it marked a transition for high yield rice. This rice, also more productive, it was more sensible to biological and environmental factors and in more need of pesticides. Pesticides in turn, influence the landscape (Karpouzas et al. [5], part of a larger Marie Curie research for the region of Pavia).

Cerghit [6] describes and classifies teaching methods. Among these are action based methods. To action based methods belongs the didactic game. Game theory is used apart of teaching in research, for simulation of decisions. In the aftermath of the Green Revolution Graham Chapman from the Department of Geography, Cambridge University, developed in the 1970s the Green Revolution Game for farmer decision making in Bihar, 


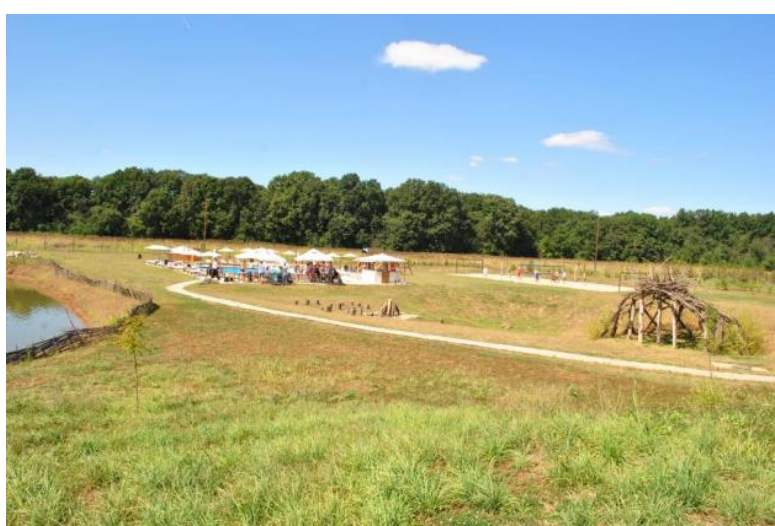

(a)

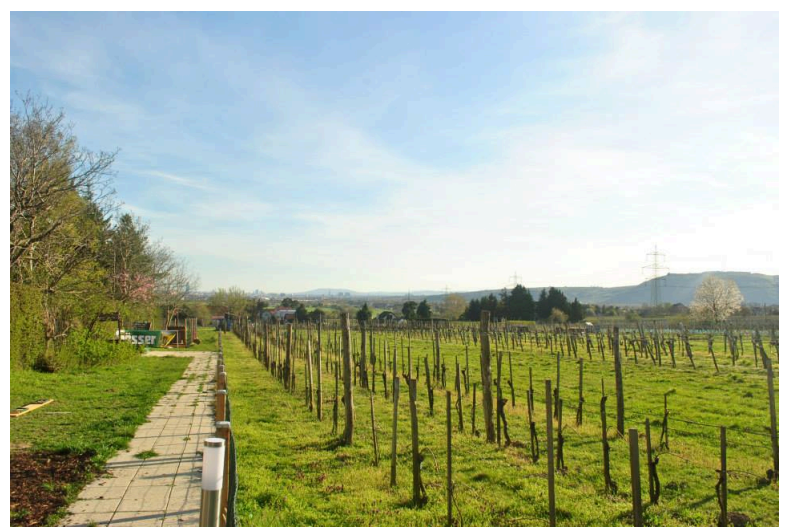

(b)

Figure 2. Urban agriculture farm near Bucharest, Romania (a) and Heuriger in Vienna (b). Photo: M. Bostenaru, 2014 and 2015.

India [7] [8]. For this purpose the reality in Bihar, India was studied extensively. The game is played by 6 - 12 farming families and a game manager. The families had different outgoing positions in what regards land ownership, family size and ownership of resources. The game manager establishes at each round the environmental conditions (drought, insects) affecting the crop in the simulated year. This happens through "chance cards" (based on the field study in Bihar) as in other simulation games (ex. Pillars of the Earth"). While rain and drought affect the whole village, pest may happen only at some farms, as well as death and birth of family members. With the technological advances acquired during the game (irrigation) the families try to respond to the environmental challenge. High yield rice bears high risk, but also high income in a short time, while a different strategy is to build up in time on irrigation, fertilizers and pesticides, which consume the money resources but do not face the risk of losing all crop and investment. The choice of strategies increases the difference between families even more than at the beginning. The game was later transformed into a board game of plastic pieces.

The game has been adapted for teaching in various universities, including the Karlsruhe University (under the name of Social laboratory: Village) and the Ohio University, in geography, including a web based component [9]. In this study it is reviewed the educational approach of the Green Revolution game and its implications for scenario building.

\section{Educational Approach}

\subsection{Simulation through Games}

In the formerly postgraduate study (today master study) of "regional science" at the University of Karlsruhe, Germany, a "Social laboratory: Village" game was conducted at the beginning, to create a data set for employment in the first study project. This variant of the Green Revolution Game was even prize awarded in 1994 as teaching prize of the land Baden-Württemberg in Germany ${ }^{3}$. It was developed by Claus Heidemann, Günter Strassert, Wilfried Wittenberg, Ute Heinzmann and Anke Rigbers. The game is a simplified version of the Green Revolution Game. As such, it does not include the variable of high yield rice. And also there is no spatial dimension, even as board game, but instead notes are being taken on paper on the development of the resources of the families over the years, from which some will be later shown in the evaluation. Other than that, it displays the same variables as in the Green Revolution Game: rice seeds, adult family members, children (who eat but do not work), money in form of rupies, fountains for irrigation, parcels.

If the game was to be classified, it is rather a competition game, since at the end of the game some families stay better than another (Figure 3), but there is no goal to be reached. At the same time, all families develop separately in the different game rounds. At the beginning of the game they have a number of adults to work, of children and adults to feed, of parcels and of money. With this they can choose to make fountains to irrigate the fields, to buy rice and fertilizer for better crops. The game leader decides the fate of a year, if there is drought.

\footnotetext{
${ }^{3}$ https://mwk.baden-wuerttemberg.de/fileadmin/redaktion/m-mwk/intern/dateien/pdf/Hochschulen/Universit\%C3\%A4ten_ab1993.pdf
} 


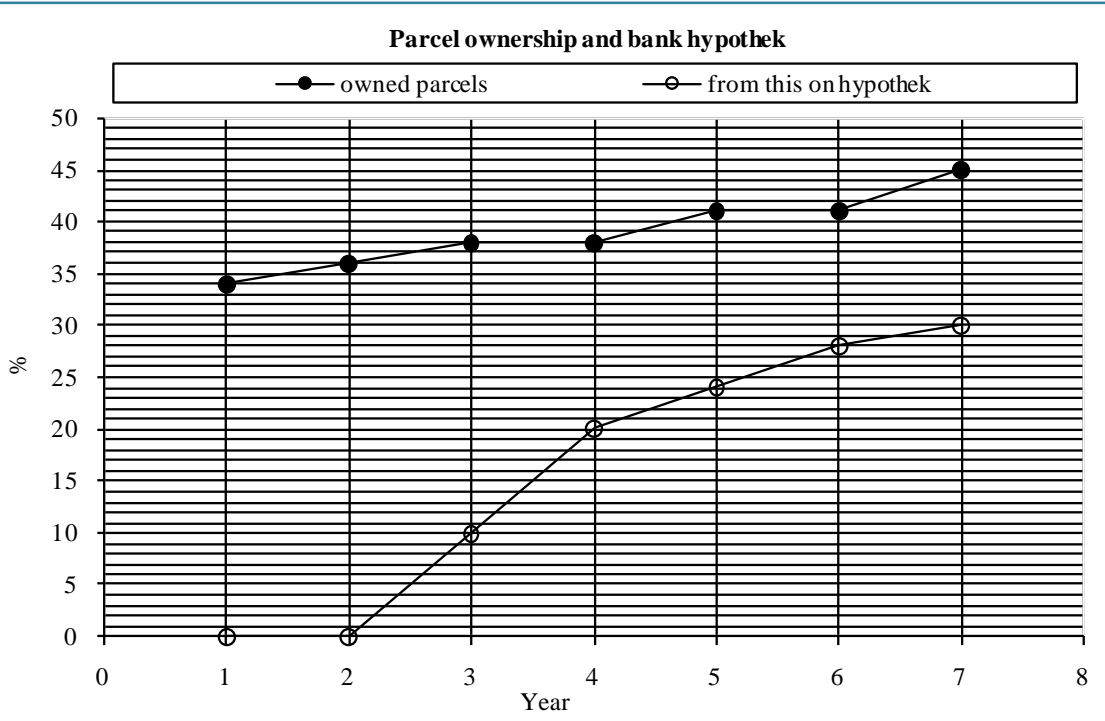

Fountains on parcels during time

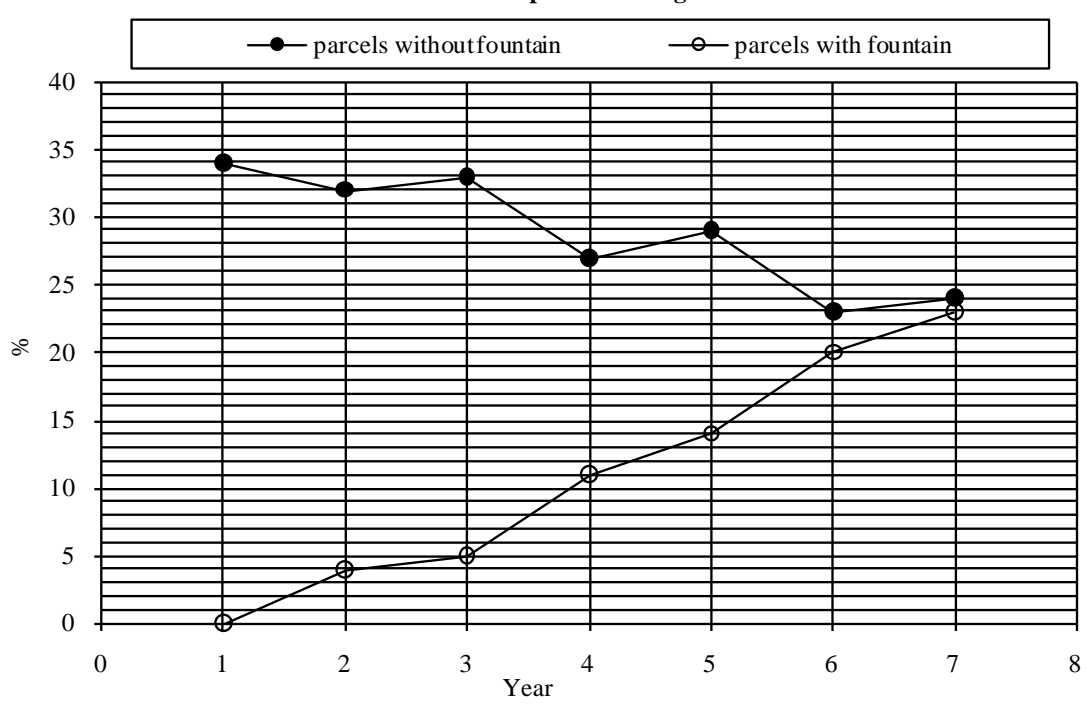

(a)

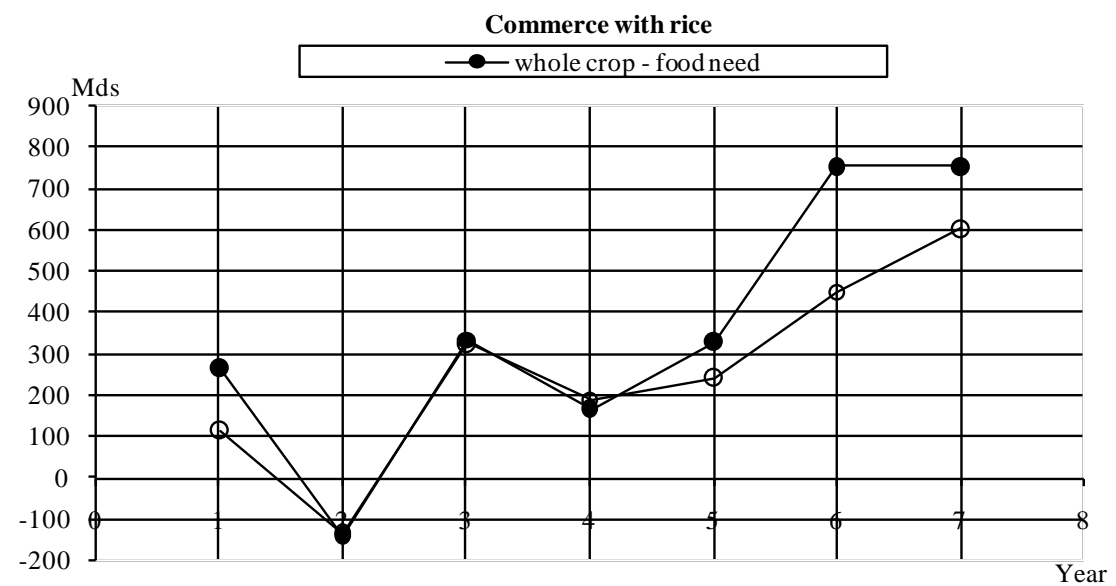

(b)

Figure 3. (a) Economic situation in social laboratory "village": loans from the bank and commerce; (b) Irrigation situation in social laboratory "village". 
Compared to the Green Revolution Game the "Social Laboratory: Village" is simplified since it does not include the option of high yield rice and low yield rice. Pesticides for high yield rice are hence not needed and the fate is given by drought or not. The contingency measure is the building of fountains, and, in case the crop is destroyed to buy new seeds for making new crops. These are bought from the bank (Figure 4).

The proposal for improving the situation in the Social laboratory: Village was to transform the game in a cooperation game. Such cooperation games are called in game theory irrigation games, however, the type of the game does not necessarily have to do with irrigation. It is much more what it is intended in this paper, namely the "network connection". Instead of buying from the bank, one family can buy from a family which has excess.

Since the focus of the postgraduate study was the developing world, the location in India was kept. For our proposal an extensive review of the kind of connections in Indian villages has been done, including internet connections.

A commerce component like the one proposed is only limitedly implemented even in social media games of today (ex. FarmVille). Even if not the best example, in FarmVille the neighbors can perform some actions such as helping to build constructions for the farm or irrigate to let plants grow faster, but they cannot help plow destroyed crops or fight against destruction of crops. Neither can they sell their crop as seeds to their neighbors.
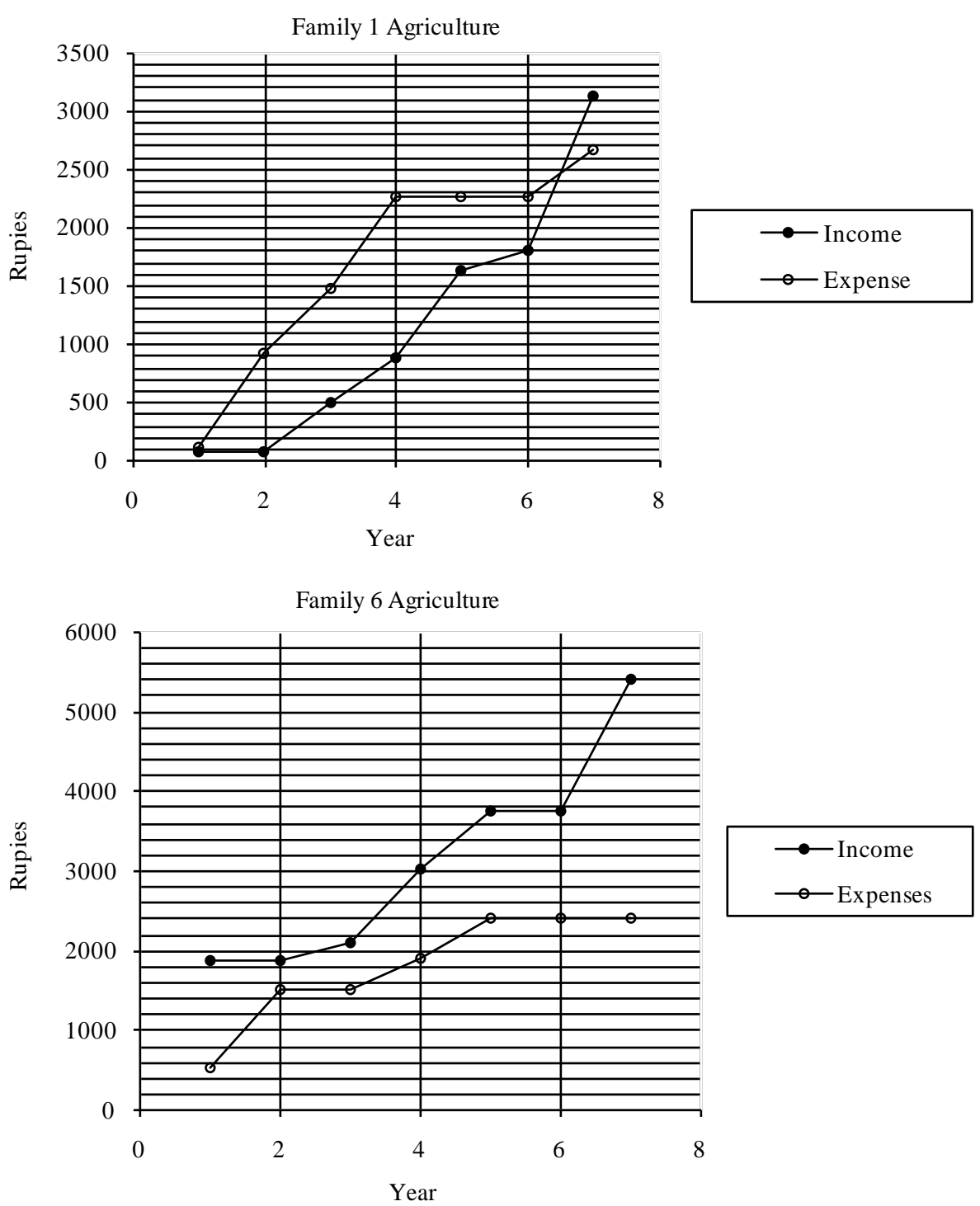

Figure 4. Economic situation of two selected families: income and expense over the 8 simulated years of run of the game. 
Unlike the Green Revolution Game, FarmVille can be classified as City Building game, a kind of construction management game. Like in the Green Revolution Game there are limited resources farmers have to manage, but the build a farm estate, visually (Figure 5) with a number of elements, which is an essential difference to Social Laboratory: Village, the output of which were descriptive statistics.

Munshi [10] discussed the social component of the Green Revolution Game, which stays in close connection with the intent of exercise of the Social Laboratory: Village.

In [11] Bostenaru et al. discussed how the vicinity of a parcel of certain value can increase that value of neighboring parcels - ex. the park in a city. In Social laboratory: Village a smaller field with a fountain could contribute to the irrigation of neighboring fields. This might lead to the necessity of topography, like in the Ohio University game.

Ahlquist [9] shows how online maps, allowed by today's cyber-technology can be employed for cyber-learning. The particular case study is an online version of the Green Revolution Game. The application at the Ohio State University uses GIS technology to provide today's experience to this game (Figure 6). An NSF award allowed for developing an educational game. Aim of the game is to learn about how much technology can help obtaining success in a small farm, as in the initial game. As in Karlsruhe, the game is integrated in the teaching process, but, while in Karlsruhe this happens at postgraduate level in regional science, in Ohio it is undergraduate geography study. Thus, instead of developing an individual study based on the data collected with the game, in Ohio the students will learn about management and be able to answer evaluation questions. Future work in the Ohio GeoGame includes cooperation possibilities as suggested in the Karlsruhe individual study as well, such as sharecropping (leasing the land to fellow farmers instead of borrowing workforce). The game is available online ${ }^{4}$ and also external users like the author can play it.

\subsection{Virtual Education}

With the 1990s a special interest started to be paid to virtual teaching, which today culminates with highly spread MOOCs. Brückner [12] proposed a multimedia learning system, and Russel [13] introduced the virtual

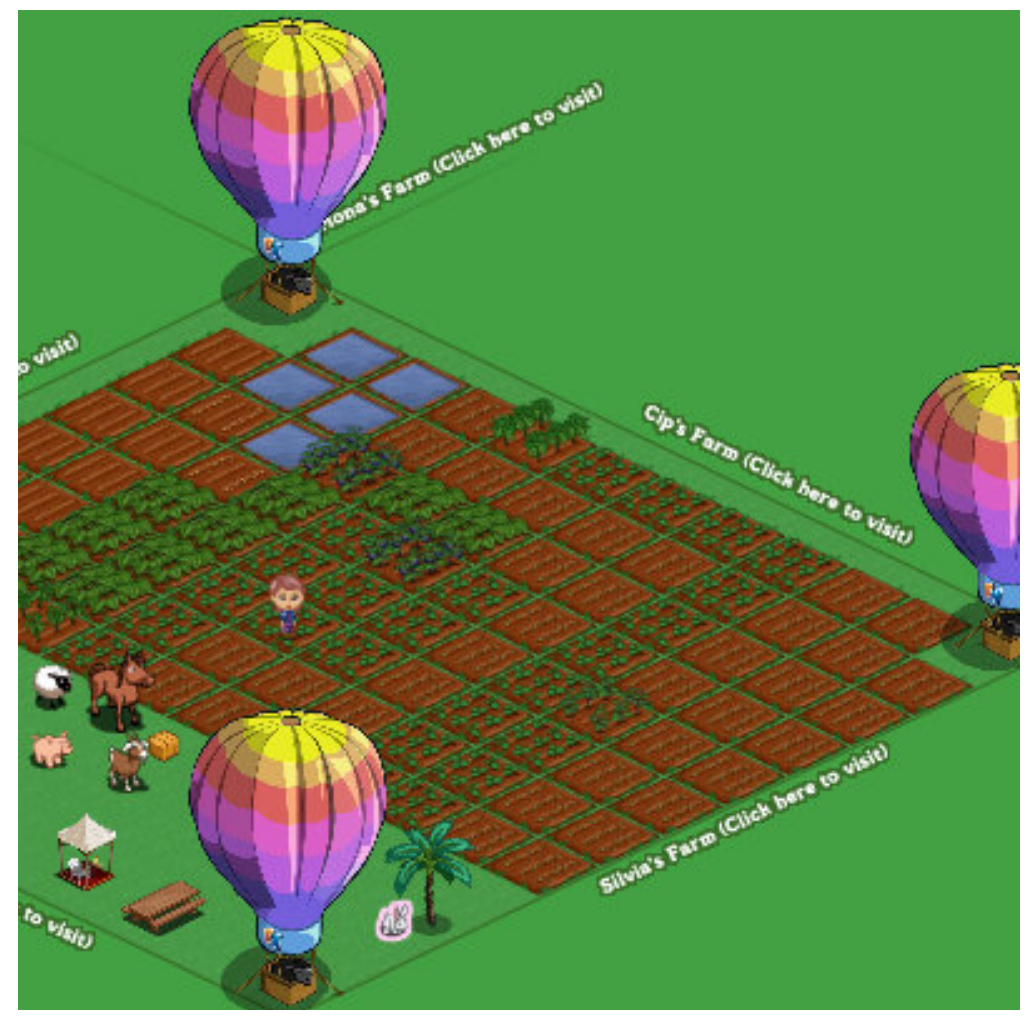

Figure 5. Results of the farmville game.

\footnotetext{
${ }^{4}$ http://geogame.osu.edu/
} 


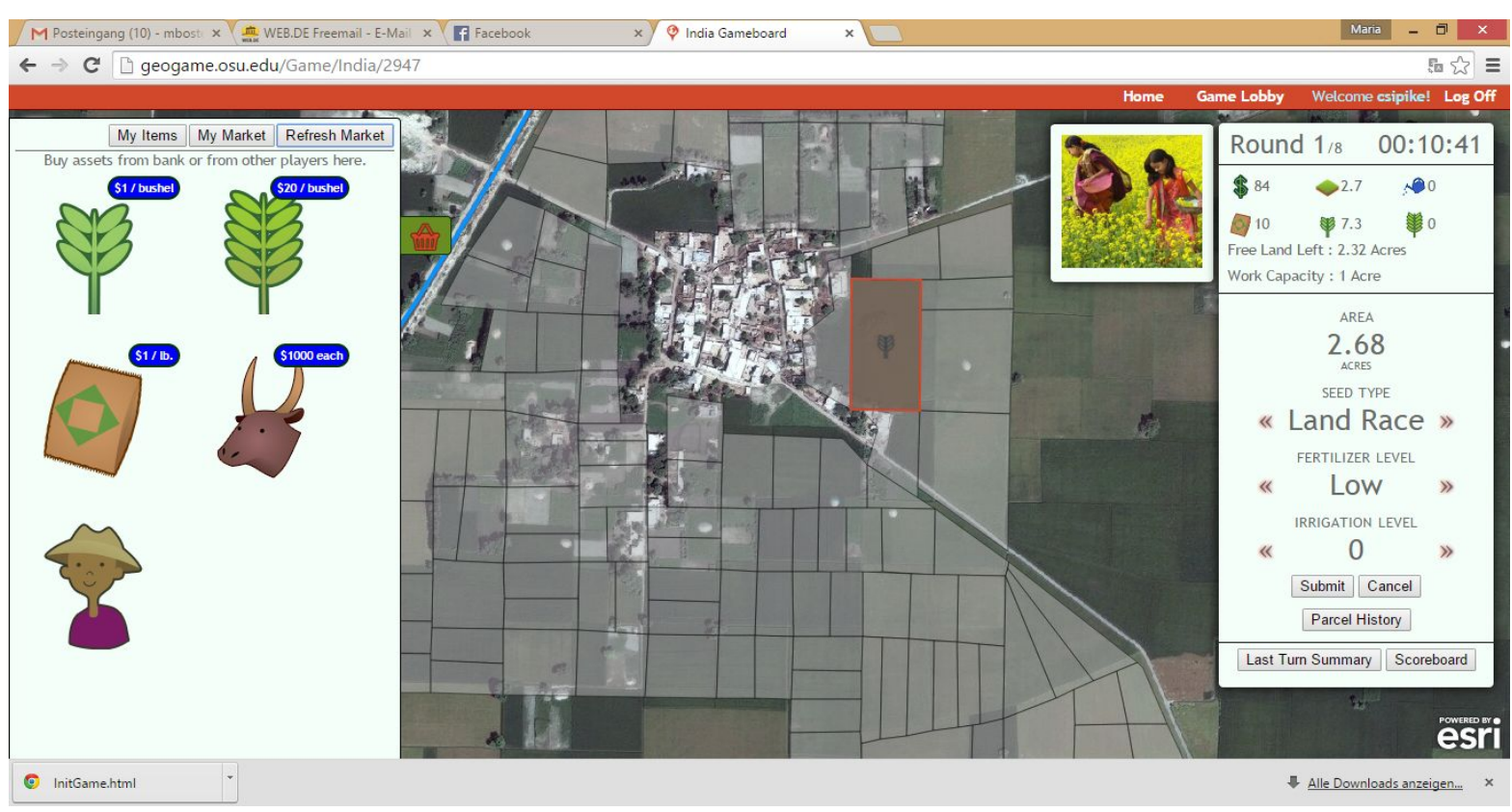

Figure 6. Interface of the geogame based on green revolution game.

studio, a collaborative platform to share project critique. Hughes [14] did a review of the multimedia development at that date, emphasizing also the development of some game and simulation applications. Today this platform is discontinued since tools of computer assisted learning are made available by internet services provides which render a special server obsolete. Both approaches were done at the University of Karlsruhe. An example on how today these new tools can be used is given by Dikigoropoulou and Bouratoglou [15] or by Bouratoglou [16].

However, as Bostenaru Dan [17] shows, the translation of the presentation of a project to the web needs more than just putting the images online, but a transformation of the concept.

For a web-game similar challenges are posed. If the simulation in Social Laboratory: Village were based only on numerical spread sheet data, for the GeoGame at the Ohio University (Figure 6), a new genre, new elements were introduced. Such, the game was localized in space, and the choice for different types of rice influences also landscape building at the end of the game. Popa [18] analyzed how such an agricultural landscape can be decoded by the lines, paths, zones, landmarks and nodes building it, different from what the underlying GIS interprets. In landscape virtual education so far the approaches of Brückner [12] are further spread. Such, Nothelfer [19] and Fetzer [20] propose learning systems but not studios of projects. A geo-game might be a proper contribution towards this. Such geo-games have been developed also by Poplin [21]. They may be played from different parts of the world, and allow intervention on a site. The city can become a virtual canvas for new projects as seen in Stan [22].

\section{Results}

The review is that of the student experience with both games. In case of the simulation at the University of Karlsruhe, the data obtained with the short simulation (2 days) of the game build a database to analyze decisions and their economic impact. The wealth of a family has to be built with limited resources on money, seeds, work force and water resources. Additional natural resources can be obtained from the bank, and there is no cooperation between the families. They develop themselves independently and comparisons can be built, as in Figure 4 . Family 6 has constantly income above the expenses, while family 1 manages to get to this state only after a number of years. Figure 3 on the contrary shows that providing with fountains is a constant and linear thread in run of the game. As money is becoming scarce from buying resources, parcels fall under hypothec. The crop is growing in amount during the game run, exceeding the food need in total and thus leading to more security. The author played this game in group and elaborated afterwards an individual study on "Network connection: improving the quality of life in Social Laboratory: Village". This implies interaction between families, forming of 
groups in the early years: instead of just interacting with the bank, interaction between more wealthy and less wealthy families (like on the examples of family 1 and family 6) in exchanging work force and exchanging seeds. As shown in Figure 3, the whole crop always exceeds the food need, regardless how bad the year. Some of these proposals are implemented in other city building games. For example the game "Pillars of the earth" includes the exchange of work force between the players, who contribute all to building the cathedral, but the one with most contribution wins the game. Also, the FarmVille game includes visits between farms, to help building a fountain or water some parcels, which might be of help in this game. The initial Green Revolution Game included a labor market as one stage before the growing season and the possibility to lend money among the farmers.

The GeoGame follows more strictly the Green Revolution Game model by including the high yield rice variable. But, with the computing power possibilities of today it give a spatial dimension. The parcels are visualized, and they unequal. Decisions in each round and gaining stability over time can be analyzed same way as in "Social Laboratory: Village", just with these more variables. Additionally, the final geo-image has a landscape component. The author played this game alone, thus all parcels were available, but thus the final image was determined only by the choice of the author of planting and not planting, and which type of rice to use. However, even these 3 variables can lead to a certain landscape image, to which it adds if the crop is destroyed by lack of water or of pesticides. As mentioned, future work will include a network connection also here, the sharecropping between farmers.

\section{Discussions}

\subsection{Implications for European Policy}

Hybrid rice cultivation in recent times in Italy has been reviewed by Tesio et al. [23]. European competitiveness today in field of agriculture leads to a new view on the Green Revolution, and the need to simulate decisions on the employment of new sorts. Variations of the Green Revolution Game presented here might be of use for scenarios.

The water framework directive effects on irrigation were an outgoing point for the work of Sali and Monaco [24]. Unlike in the game, where irrigation was done through fountains, irrigation in northern Italy is connected to flooded rice fields. These have a changed habitat from an ecological point of view, and also the climate of the city is changed through it. In Pavia in winter there is fog and in summer mosquitoes due to extensive irrigation of the rice. The fog landscape is a totally different landscape of the irrigated terraces in Japan.

Other elements of the game which have a correspondent in real life are the fertilizer to increase crops reviewed for example by Bocchi and Malgioglio [25] and the herbicides reviewed by Rubino et al. [26]. Sparacino et al. [27] brings in connection herbicides and water use.

In Europe wine cultures are better known for urban agriculture [28] [29]. The value of new settlements is being increased following the model of the Italian villa which had a productive function, in today's implementation of European structural funds. Such an example is the one in Figure 2. For rice still similar implications of agricultural tourism as for wine have to look for. The plains in Pavia are less spectacular than the terraces in Japan, or even those well known of Tuscany, but the culinary use of rice in Mediterranean/Italian kitchen is well known.

In 2012 during the first meeting of Cultural Routes of Europe that took place in Pavia the role of different religious and heritage routes around the city was emphasized. More recently, initiatives of UniScape, concerned with the implementation of the European Landscape Convention are dedicated to such routes in Italy. They concern the agricultural landscape through which the route goes from one landmark to another. The rice culture may be a valuable asset to be investigated after the method of Popa [18].

Finally, regarding geo-games, the contribution of O'Caroll et al. [30] on virtual mobility is worth to be mentioned. A workshop at the EuroScience Open Forum in Copenhagen led to conclusions regarding the contribution of virtual mobility today. While for learning of the Karlsruhe experience in playing the Social laboratory: Village game it was necessary to be there as an enrolled student, the Ohio university GeoGame can be played over the net. From the point of view of learning and of research as well virtual mobility can extend the participation base. But, for learning about the consequences of design decisions of urban agriculture in this case, it is necessary to know the local conditions, to investigate the landscape by walking along the route. This is why, although the learning game was for India, a case study in Europe about which the authors knows was looked for this article. During the Marie Curie fellowships of the author time was spent in the city of Pavia, the "capital" of 
rice in Italy. The advantages and disadvantages of different kinds of mobility may help the European Commission to better configure such scholarship support programs.

\subsection{Ecological Implications}

Kiley-Worthington [31] analyzed the implications of farming on ecology. It is to be highlighted that in case of urban agriculture as in Figure 2 or in the geo-game, the vicinity of forest can be kept. On the other hand, rice cultures are artificial wetlands which are proper habitat for birds, as analyzed by Fasola [32]. It is the topic also in Thomas et al. [33], and a conference session was also organized on the topic ${ }^{5}$. With increasing urbanization, urban agriculture as this kind as we saw in Figure 1 is a chance for creating habitat for herons and egrets. The game highlights the role of irrigation as shown in Figure 3, which must be extensive enough to allow also the wild habitat apart of the agricultural use.

As in Hernández-Delgado et al. [34] the simulation in "social laboratory—village" emphasizes the role of participation and community involvement in case of influences of climate change. In this case it is about the influence of climate change on agriculture. Munshi [10] already highlighted the role of social learning in the Green Revolution game. Our data prove that networking in "social laboratory—village" is benefic for overcoming effects of climate change such as drought effects on crops and decrease of the seed availability for the next year/round through mutual help instead of dependence on the bank. Protection of green spaces with their habitat is something what has to be born first in the heads of people, as an idea, before protection through legislation, as the major of Frankfurt showed in the Green Belt year. Green Belts are such a landscape structure, other than in Ziman Scudo [3], which include urban agriculture, to be explored with the method of Popa [18].

The Green Revolution was aiming at producing higher yield rice which however was more sensible to draught and in more need of pesticides. Joshi et al. [35] and Prashar et al. [36] show new organic fertilizers with effects on yield. Verma et al. [37] instead shows the way pesticides may be biodegraded. Several decades after the Green Revolution game, Joshi et al. [35] is employed in rural India as shown in Suthar [38] and can lead to socio-economic effects. Since the socio-economic effects are subject of the Green Revolution game, this may be updated as in terms of the "social laboratory: village" (which does not use high yield rice anymore) not only of virtual implementation in GIS as in the geo-game. Kanfany et al. [39] shows the effects of fertilizers on yield as in the game.

India and generally Asia are not the only ones where the Green Revolution took place. In some places like South America seed conservation is still a problem today, as in the simulation game, as shown by a recent paper [40]. Ecological agriculture is the answer. The case study refers to the Green Belt of a city, and hence to urban agriculture as in our considered European case study (and discussed for the Frankfurt Green Belt and community participation).

Such small scale farming as seen in Figure 1 and in Bonicatto et al. [40] may be the solution for conserving biodiversity in rice production. Luo et al. [41] conducted a study in this regard observing the characteristics of wetlands mentioned above but also the increase of insects and need of pesticides. The Green Revolution game analyses such aspects in the GeoGame version. There parcels of different sizes and at different locations can be chosen, and also the amount of irrigation.

Yuan and colleagues [42] analyzed the maintenance of traditional knowledge for ecological and sustainable agriculture. As in case of Luo et al. [41], it is located in Asia, one of the partners in the rice coalition of the Milan expo, but not in India where the Green Revolution game was developed. It is located in China. Traditional knowledge influences water management in the culture of rice, which, as seen in the game, is important for protection from drought as effect of climate change. But we've also seen that water management influences biodiversity Luo et al. [41], including that in Fasola [32] and Thomas et al. [33]. Rabbani et al. [43] goes in detail regarding the climate change influence on wetland ecosystems. These include alternate rice and vegetable farming. The farming considered is small scale, hence in line with the findings of Bonicatto et al. [40] regarding biodiversity, but the irrigation includes new aspects compared to "social laboratory: village" namely access to ponds instead of creating fountains. This would give the new dimension of the game of an irrigation game mentioned. Sites considered are also Asia, but coastal Bangladesh.

The Green Revolution aimed at creating more productive rice, which is a problem for policy also today, as seen. But, today the challenge is different, it is climate change. Both games consider the effects of climate

${ }^{5}$ http://pe.ska.life.tsukuba.ac.jp/PES30/?q=en/content/symposia_en/organized_en/So3_en 
change through the modeling of drought. Access to water is vital for this artificial wetland culture. However, today new types of rice are developed which are more draught resistant [44]. This has a positive impact on agriculture, but it might destroy biodiversity, which depends on extensive wetland.

Chen et al. [45] gives a scale of the climate change related disasters, flood and drought, in real life for rice cultures in China. The games proposed analyze it on the small scale which is suitable for urban agriculture simulations relevant for biodiversity as well. Returning to Bangladesh, this is detailed in Ruhul Amin et al. [46].

\section{Conclusion}

In this study, the contribution of a certain area of urban geography was reviewed: the landscape of urban agriculture. Based on older and newer developments in implementing the decision simulation in the Green Revolution game, conclusions can be drawn towards the type of game most adequate for another time and another site. The game can, or cannot, have a spatial component. The two reviewed games renounced and respectively improved the spatial component compared to the Green Revolution Game which served as their model. The game simulation in itself as presented for the University of Karlsruhe included the creation of a set of data for later study projects to propose the improvement of the run off of the game for certain families. The present study included a scenario of cooperation between families, which may lead to a spatial component (ex. identifying neighboring families). Regional science as in Karlsruhe may have a more strong component in economy, and as such the geography employment may turn towards economic geography. Social learning is also important, on what technology may lead to economic success under certain environmental conditions. The proposed network connection is an element of this social learning. The Green Revolution Game and the two reviewed adaptations being educational games, the social learning is at the level of education. It employs the method of simulation which is a method of active learning. The game provides with management data, but the player does not immerse in the world as in virtual reality games such as second life. As other online farming games show, the geographic connection does not need to be displayed and may be only quantified, while the look of the farm itself may help game experience. The look of the farm during the game, with the layout of the parcels on the field, the different types of rice, the connection to trees and buildings can allow for a next dimension of the game: the landscape analysis. For this kind of landscape project there are a number of tools available for virtual cooperation, which have not yet been used enough, as efforts are being done more in the direction of teaching environments based on lectures and not on virtual action through game and simulation. Given the need of specialists seen in European policy directions this part of teaching has to be developed more. The geographical dimension of the game permits assessing a series of aspects relevant to bio-conservation, such as the size of the parcels and their location in the vicinity of urban or natural areas. Knowledge about different farm regions than India may lead to lessons in those areas. The wealth of literature may allow this application. The game itself is suitable for urban agriculture, where small parcels are the correspondent of small farms. This way the game helps to simulate and understand the benefits of sustainability.

\section{Acknowledgements}

The review in this article is part of the postdoctoral grant supported by the strategic grant POSDRU/159/1.5/ S/133391, Project "Doctoral and Post-doctoral programs of excellence for highly qualified human resources training for research in the field of Life sciences, Environment and Earth Science" cofinanced by the European Social Found within the Sectorial Operational Program Human Resources Development 2007-2013. The paper also serves the scope of the COST network IS1104.

\section{References}

[1] Confalonieri, R. and Bocchi, S. (2005) Evaluation of CropSyst for Simulating the Yield of Flooded Rice in Northern Italy. European Journal of Agronomy, 23, 315-326. http://dx.doi.org/10.1016/j.eja.2004.12.002

[2] Takaya, Y., Kyuma, K. and Kawaguchi, K. (1974) Rice Cultivation and Its Environmental Conditions in the Mediterranean Countries I. Climate and Physiography in Relation to Rice Cultivation. Soil Science and Plant Nutrition, 20, 209-223. http://dx.doi.org/10.1080/00380768.1974.10433244

[3] Scudo, K.Z. (2006) The Greenways of Pavia: innovations in Italian landscape planning. Landscape and Urban Planning, 76, 112-133. http://dx.doi.org/10.1016/j.landurbplan.2004.09.030 
[4] Stan, A. (2014) The Landscape of the Urban Peripheries: An Alternative Therapy. In: Crăciun, C. and Bostenaru Dan, M., Eds., Planning and Designing Sustainable and Resilient Landscapes, Springer Geography, Dordrecht, 117-126. http://dx.doi.org/10.1007/978-94-017-8536-5_9

[5] Karpouzas, D.G., Ribarbelli, C., Pastori, M. and Capri, E. (2006) Landscape Risk Analysis for Pesticides Applied to Rice Paddies. Agronomy for Sustainable Development, 26, 167-177. http://dx.doi.org/10.1051/agro:2006013

[6] Cerghit, I. (2006) Metode de invatamant. Polirom, Jassy.

[7] Chapman, G.P. (1973) The Green Revolution: A Gaming Simulation. The Royal Geographical Society (with the Institute of British Geographers), 5, 129-140.

[8] Corbridge, S. (1985) The Green Revolution Game. Journal of Geography in Higher Education, 9, 171-175. http://dx.doi.org/10.1080/03098268508708939

[9] Ahlqvist, A. (2011) Converging Themes in Cartography and Computer Games. Cartography and Geographic Information Science, 38, 278-285. http://dx.doi.org/10.1559/15230406382278

[10] Munshi, K. (2004) Social Learning in a Heterogeneous Population: Technology Diffusion in the Indian Green Revolution. Journal of Development Economics, 73, 185-213. http://dx.doi.org/10.1016/j.jdeveco.2003.03.003

[11] Bostenaru Dan, M., Aldea Mendes, D. and Panagopoulos, T. (2013) Assessing the Costs of Hazards Mitigation in the Urban Structure. Journal of Biourbanism, III, 51-68. http://journalofbiourbanism.org/2014/05/07/assessing-the-costs-of-hazards-mitigation-in-the-urban-structure/

[12] Brückner, T. (1998) Ein WWW Basiertes Lernsystem zum Thema Internet (Diploma Work). University of Karlsruhe, Karlsruhe.

[13] Russell, P. (2001) Creating Place in the Virtual Design Studio. In: Russell, P., Ed., CAAD Futures, Springer Netherlands, Dordrecht, 231-242. http://dx.doi.org/10.1007/978-94-010-0868-6_18

[14] Hughes, B. (1999) Dust or Magic. Secrets of Successful Multimedia Design (Reprinted as Creative Work in The Digital Age). Addison-Wesley, Harlow.

[15] Dikigoropoulou, L. and Bouratoglou, J. (2014) Global Interaction into the Traditional Design Studios through Blogs. 4th Annual International Conference on Architecture, Athens, 7-10 July 2014, 7-10.

[16] Bouratoglou, J., Dikigoropoulou, L., Dubon, G., Bostenaru Dan, M. and Doczy, P. (2015) Research by Design in the Architecture of Spa-S. Argument, 7. (Section: from the works of students)

[17] Bostenaru Dan, M. (2015) “Hard Copy” Building Model versus Digital Webpage Serving the Representation of Concepts in Architecture Design and in Scenographic Design. Review of European Studies, 7, 210-228. http://dx.doi.org/10.5539/res.v7n3p210

[18] Popa, A. (2014) Decoding Agricultural Landscape. In: Crăciun, C. and Bostenaru Dan, M., Eds., Planning and Designing Sustainable and Resilient Landscapes, Springer Geography, Dordrecht, 33-41. http://dx.doi.org/10.1007/978-94-017-8536-5_3

[19] Nothelfer, U. (2008) Landschaftsarchitekturausbildung-Zwischen Topos und topologischem Denken: Medienpädagogische Grundzüge eines webbasierten Fernstudiums, orientiert an signifikanten Lern- und Lehrerfahrungen in der Landschaftsarchitekturausbildung seit ihren Ursprüngen (after a PhD work at the University of Kaiserslautern). Der Andere Verlag, Lübeck.

[20] Fetzer, E. (2014) Knowledge Building in Landscape Architecture: A Pedagogical Action Research Study with International Online Seminars. Kassel University Press, Kassel.

[21] Poplin, A. (2012) Playful Public Participation in Urban Planning: A Case Study for Online Serious Games. Computers, Environment and Urban Systems (CEUS), 36, 195-206. http://dx.doi.org/10.1016/j.compenvurbsys.2011.10.003

[22] Stan, A. (2014) The City’s Creative Writing: From Morphology to Virtual Landscape. Procedia-Social and Behavioral Sciences, 149, 901-905. http://dx.doi.org/10.1016/j.sbspro.2014.08.279

[23] Tesio, F., Tabacchi, M., Cerioli, S. and Follis, F. (2014) Sustainable Hybrid Rice Cultivation in Italy. A Review. Agronomy for Sustainable Development, 34, 93-102. http://dx.doi.org/10.1007/s13593-013-0157-6

[24] Sali, G. and Monaco, F. (2014) Irrigation Water Resource in a Rice-Growing Area: Economic Evaluation under Different Pricing Conditions. In: Sali, G. and Monaco, F., Eds., Agricultural Cooperative Management and Policy: New Robust, Reliable and Coherent Modelling Tools, Springer, Dordrecht, 23-40. http://dx.doi.org/10.1007/978-3-319-06635-6_2

[25] Bocchi, S. and Malgioglio, A. (2010) Azolla-Anabaena as a Biofertilizer for Rice Paddy Fields in the Po Valley, a Temperate Rice Area in Northern Italy. International Journal of Agronomy, 2010, Article ID: 152158. http://dx.doi.org/10.1155/2010/152158

[26] Rubino, F.M., Mandic-Rajcevic, S., Ariano, E., Alegakis, A., Bogni, M., Brambilla, G., De Paschale, G., Firmi, A., Minoia, C., Micoli, G., Savi, S., Sottani, C., Somaruga, C., Turci, R., Vellere, F., Tsatsakis, A. and Colosio, C. (2012) 
Farmers' Exposure to Herbicides in North Italy: Assessment under Real-Life Conditions in Small-Size Rice and Corn Farms. Toxicology Letters, 210, 189-197. http://dx.doi.org/10.1016/j.toxlet.2012.01.017

[27] Sparacino, A.C., Tano, F., Ferro, R., Ditto, D., Riva, N. and Braggio, R. (2002) Effects of Water Management and Herbicide Treatments on Red Rice Control. Mededelingen (Rijksuniversiteit te Gent. Fakulteit van de Landbouwkundige en Toegepaste Biologische Wetenschappen, 67, 441-449.

[28] Mihaila, M. (2011) Wine Tourism-Architecture and Landscape. In: Dabija, A.M., Ed., Urban Space-Architectural Space - Interior Space, Chapter Urban Space, EUIM — Ion Mincu University Publishing House, Bucharest, 41-48.

[29] Mihaila, M. and Banica, C. (2014) Wine Regions and Wine Tourism. Integrated Wine Architecture for Romania. International Conference on the Role of Tourism in Territorial Development, Faculty of Geography, Babes-Bolyai University Cluj-Napoca, Gheorgheni, 10 October 2014, 98-107.

[30] O’Carroll, C., Scholz, B., Nogueira, M.M., Avellis, G., Marin, L., Bostenaru Dan, M., Chmielowski, R., di Trapani, A. and Theodoridou, M. (2014) Careers: Virtual Mobility Can Drive Equality. Nature, 511, 292. http://dx.doi.org/10.1038/511292b

[31] Kiley-Worthington, M. (2014) Ecological Agriculture. Integrating Low Input, High Productive Farming with Wildlife Conservation. Results from the Experimental Farm La Combe, Drome France. Open Journal of Ecology, 4, 744-763. http://dx.doi.org/10.4236/oje.2014.412064

[32] Fasola, M. (1983) Nesting Populations of Herons in Italy Depending on Feeding Habitats. Bolletino di Zoologia, 50, 1-2, 21-24.

[33] Thomas, P., Martin, P. and Boutin, C. (2011) Bush, Bugs, and Birds; Interdependency in a Farming Landscape. Open Journal of Ecology, 1, 9-23. http://dx.doi.org/10.4236/oje.2011.12002

[34] Hernández-Delgado, E., Mercado-Molina, A., Alejandro-Camis, P., Candelas-Sánchez, F., Fonseca-Miranda, J., GonzálezRamos, C., Guzmán-Rodríguez, R., Mège, P., Montañez-Acuña, A., Maldonado, I., Otaño-Cruz, A. and Suleimán-Ramos, S. (2014) Community-Based Coral Reef Rehabilitation in a Changing Climate: Lessons Learned from Hurricanes, Extreme Rainfall, and Changing Land Use Impacts. Open Journal of Ecology, 4, 918-944. http://dx.doi.org/10.4236/oje.2014.414077

[35] Joshi, R., Singh, J. and Vig, A.P. (2015) Vermicompost as an Effective Organic Fertilizer and Biocontrol Agent: Effect on Growth, Yield and Quality of Plants. Reviews in Environmental Science and Bio/Technology, 14, 137-159. http://dx.doi.org/10.1007/s11157-014-9347-1

[36] Prashar, P., Kapoor, N. and Sachdeva, S. (2014) Rhizosphere: Its Structure, Bacterial Diversity and Significance. Reviews in Environmental Science and Bio/Technology, 13, 63-77. http://dx.doi.org/10.1007/s11157-013-9317-z

[37] Verma, J.P., Jaiswal, D.K. and Sagar, R. (2014) Pesticide Relevance and Their Microbial Degradation: A-State-of-Art. Reviews in Environmental Science and Bio/Technology, 13, 429-466. http://dx.doi.org/10.1007/s11157-014-9341-7

[38] Suthar, S. (2011) Utilizing Livestock Waste Solids as Bioresource for Socio-Economic Sustainability: A Report from Rural India. Reviews in Environmental Science and Bio/Technology, 10, 193-197. http://dx.doi.org/10.1007/s11157-011-9240-0

[39] Kanfany, G., El-Namaky, R., Ndiaye, K., Traore, K. and Ortiz, R. (2014) Assessment of Rice Inbred Lines and Hybrids under Low Fertilizer Levels in Senegal. Sustainability, 6, 1153-1162. http://dx.doi.org/10.3390/su6031153

[40] Bonicatto, M.M., Marasas, M.E., Sarandona, S. and Pochettino, M.L. (2015) Seed Conservation by Family Farmers in the Rural-Urban Fringe Area of La Plata Region, Argentina: The Dynamics of an Ancient Practice. Agroecology and Sustainable Food Systems, 39, 625-646. http://dx.doi.org/10.1080/21683565.2015.1020405

[41] Luo, Y., Fu, H. and Traore, S. (2014) Biodiversity Conservation in Rice Paddies in China: Toward Ecological Sustainability. Sustainability, 6, 6107-6124. http://dx.doi.org/10.3390/su6096107

[42] Yuan, Z., Lun, F., He, L., Cao, Z., Min, Q., Bai, Y., Liu, M., Cheng, S., Li, W. and Fuller, A.M. (2014) Exploring the State of Retention of Traditional Ecological Knowledge (TEK) in a Hani Rice Terrace Village, Southwest China. Sustainability, 6, 4497-4513. http://dx.doi.org/10.3390/su6074497

[43] Rabbani, G., Rahman, S.H. and Faulkner, L. (2013) Impacts of Climatic Hazards on the Small Wetland Ecosystems (ponds): Evidence from Some Selected Areas of Coastal Bangladesh. Sustainability, 5, 1510-1521. http://dx.doi.org/10.3390/su5041510

[44] Pray, C., Nagarajan, L., Li, L., Huang, J., Hu, R., Selvaraj, K.N., Napasintuwong, O. and Chandra Babu, R. (2011) Potential Impact of Biotechnology on Adaption of Agriculture to Climate Change: The Case of Drought Tolerant Rice Breeding in Asia. Sustainability, 3, 1723-1741. http://dx.doi.org/10.3390/su3101723

[45] Chen, Q., Zhang, J., and Zhang, L. (2015) Risk Assessment, Partition and Economic Loss Estimation of Rice Production in China, Sustainability, 7, 563-583. http://dx.doi.org/10.3390/su7010563

[46] Ruhul Amin, Md., Zhang, J. and Yang, M. (2015) Effects of Climate Change on the Yield and Cropping Area of Major Food Crops: A Case of Bangladesh. Sustainability, 7, 898-915. http://dx.doi.org/10.3390/su7010898 